Finisterra, XXXV, 70, 2000, pp. 89-101

\title{
CONSIDERAÇÕES ACERCA DO ARREFECIMENTO PLISTOCÉNICO EM PORTUGAL
}

\author{
ANTÓNIO DE BRUM FerReira 1
}

\begin{abstract}
Resumo - Com base na reconstituição feita pelos membros do Projecto CLIMAP (1976) sobre as condições ambientais da Terra há 18000 anos e no Atlas dos Paleoclimas e Paleoambientes do Hemisfério Norte, no Plistocénico Superior e no Holocénico (Frenzel et al., 1992), caracterizam-se as condições prevalecentes no Atlântico Norte e na Europa Ocidental durante o Máximo Arrefecimento da Última Glaciação. Tendo em atenção este quadro de condições climáticas extremas e as características das manifestações glaciárias e periglaciárias da Península Ibérica, procura-se avaliar o grau de arrefecimento em Portugal compatível com a glaciação das serras do Gerês e da Estrela. Conclui-se que o cenário mais provável é o de um abaixamento da ordem de $10^{\circ} \mathrm{C}$ nas temperaturas de Verão.
\end{abstract}

Palavras-chave: Paleoclimas, Plistocénico Superior, Portugal.

Abstract - Note on the Pleistocene cooling in Portugal - Prevailing conditions in the North Atlantic and Western Europe during the Maximum Cooling of the Last Glaciation can be deduced from the Climap Project (1976) results and from the Atlas of Paleoclimates and Paleoenvironments of the Northern Hemisphere (FRENZEL et al., 1992). Taking into account this framework of extreme climatic conditions and the nature of the glacial and periglacial relict phenomena in the Iberian Peninsula, an attempt is made to evaluate the degree of cooling in Portugal during the Gerês and Estrela glaciations. A drop of about $10^{\circ} \mathrm{C}$ in summer temperatures is suggested.

Key words: Paleoclimates, Late Pleistocene, Portugal.

1 Investigador do Centro de Estudos Geográficos, Professor Catedrático da Universidade de Lisboa (endereço do CEG no início do volume). 
As glaciações do Plistocénico traduziram-se em transformações radicais da geografia física da Terra. Neste sentido, as características ambientais do período de Máximo Arrefecimento da Última Glaciação (intervalo 20000 - 18000 anos B.P.) revestem-se de um interesse científico particular, porque representam as modificações ambientais mais extremas em relação às condições actuais.

O estudo das características climáticas desse último intervalo de tempo constituiu um dos principais objectivos do Projecto CLIMAP, que apresentou como realização mais saliente a já célebre reconstituição das condições da superfície da Terra, há 18000 anos, nomeadamente no que se refere à temperatura da superfície dos oceanos (CLIMAP, 1976). Mas as investigações nos continentes são mais antigas, e multiplicaram-se em domínios tão diversos como a glaciologia, a geomorfologia glaciária e periglaciária, o estudo dos loess, dos solos, das floras e das faunas. Essa variadíssima informação, de valor díspar e, por vezes, de difícil interpretação, foi recentemente sintetizada num notável trabalho de cartografia, realizado sob os auspícios da INQUA (Associação Internacional para o Estudo do Quaternário), o Atlas de Paleoclimas e Paleoambientes do Hemisfério Norte, no Plistocénico Superior e no Holocénico (Frenzel et al., 1992).

Com base nessas duas realizações, caracteriza-se nesta nota o quadro natural do Atlântico Norte e da Europa Ocidental durante o Máximo Arrefecimento da Última Glaciação, e, tendo em conta, por um lado, este quadro paleogeográfico, e, por outro, os vestígios conhecidos das manifestações glaciárias e periglaciárias plistocénicas na Península Ibérica, procura-se retirar algumas ilacções acerca do grau de arrefecimento atmosférico em Portugal no Plistocénico Superior.

\section{CONSEQUÊNCIAS AMBIENTAIS DAS GLACIAÇÕES QUATERNÁRIAS}

As glaciações do Quaternário provocaram espectaculares modificações na geografia física da Terra, em intervalos de tempo muito curtos, à escala geológica. Essas modificações, nomeadamente no Máximo da Última Glaciação, e em comparação com os períodos interglaciários, podem resumir-se do seguinte modo: 1) arrefecimento geral da atmosfera, sobretudo nas latitudes extratropicais; 2) formação dos inlandsis Norte-Europeu e Norte-Americano; 3) importante descida do limite das neves perpétuas nas regióes temperadas (várias centenas de metros), e correlativo desenvolvimento dos glaciares de montanha; 4) formação de largas faixas de permafrost à frente dos inlandsis (várias centenas de quilómetros de largura); 5) descida do limite da floresta em latitude (centenas de quilómetros) e em altitude (centenas de metros), com correlativa expansão da zona fria e do andar alpino; 6) importantes modificações nas floras continentais (migração, selecção); 7) descida do nível geral dos oceanos (mais de uma centena de metros); 8) grande arrefecimento das águas oceânicas nas latitudes extratropicais e modificações nas biocenoses marinhas. 
De um modo geral, pode falar-se num acentuado alargamento da zona fria e numa forte contracção da zona temperada. Nos continentes, há, essencialmente, a considerar: 1) a grande extensão das áreas cobertas pelos glaciares regionais, com o aparecimento dos citados inlandsis Norte-Europeu e Norte-Americano; 2) a grande extensão das áreas com permafrost, ou seja, com solo sempre gelado. Os contrastes na repartição espacial dos inlandsis, por um lado, e do permafrost, por outro, correspondem a um contraste climático fundamental: enquanto a formação dos glaciares regionais se relaciona com um clima frio e húmido, com elevada precipitação nivosa, o solo sempre gelado desenvolve-se em climas muito frios e secos, com fracas quedas de neve (a cobertura de neve tem o efeito de isolador térmico, inibindo a formação do permafrost). Por sua vez, nos oceanos, o aspecto essencial das modificações ambientais foi a grande extensão da banquisa estacional, que deve ter contribuído para uma importante sazonalidade dos climas.

\section{CONDIÇÕES AMBIENTAIS NA EUROPA OCIDENTAL E NO ATLÂN- TICO NORTE, NO PERÍODO DE MÁXIMO ARREFECIMENTO DA ÚLTIMA GLACIAÇÃO}

Na figura 1 sintetizam-se alguns dados das condições paleogeográficas prevalecentes na Europa Ocidental e no Atlântico Norte durante o período de Máximo Arrefecimento da Última Glaciação (intervalo 20000 - 18000 B.P.), com base no Atlas atrás referido (Frenzel et al., 1992).

$\mathrm{Na}$ Europa, o inlandsis estendia-se até à Alemanha e cobria a maior parte das Ilhas Britânicas, enquanto, no continente, o permafrost contínuo estendia-se ao sul do inlandsis numa faixa com uma largura aproximada de $600 \mathrm{~km}$. Na metade Sul da França, dominavam, sucessivamente, o permafrost descontínuo e esporádico, e o solo gelado estacional profundo. Este último ocupava também o Norte da Espanha, ficando o resto da Península Ibérica fora do domínio periglaciário propriamente dito, ou seja, da morfogénese dominada pela acção do gelo no solo. Evidentemente, estamos a falar em termos gené-ricos, da variação das condições ambientais segundo a latitude; é óbvio que a altitude, a exposição e outros factores geográficos, introduzem localmente fortes modificações a este esquema geral.

As condições ambientais prevalecentes no Atlântico Norte baseiam-se na reconstituição, feita pelos Membros do Projecto CLIMAP (1976), da temperatura das águas superficiais oceânicas, há 18000 anos B.P. Esta reconstituição só foi possível graças, por um lado, à estratigrafia global fornecida pelos registos dos isótopos de oxigénio, e, por outro, ao desenvolvimento de métodos quantitativos aplicados à interpretação de biotas fósseis conservados nos fundos oceânicos, e que, no caso do Atlântico, são sobretudo foraminíferos planctónicos (Неснт, 1985). Um dos aspectos mais salientes é a existência de um forte gradiente das temperaturas superficiais oceânicas, que revelam o posicionamento da frente polar oceânica, durante o Verão (Agosto), à latitude 


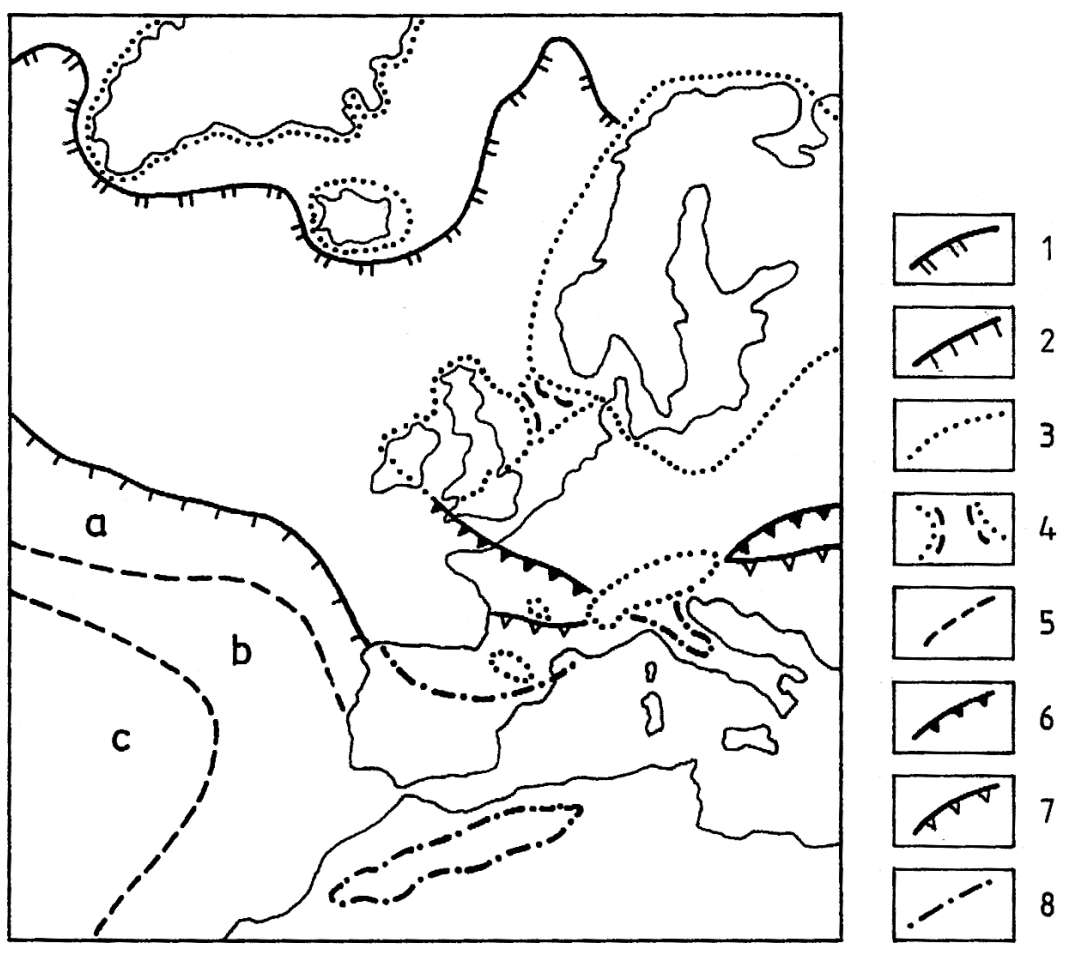

Fig. 1 - Paleogeografia da Europa Ocidental e do Atlântico Norte, no período de Máximo Arrefecimento da Última Glaciação (entre 20000 e 18000 anos B.P.). Segundo Atlas of Paleoclimates... (Frenzel et al., 1992, pp. 49 e 59; simplificado). 1 - Limite meridional da banquisa permanente; 2 - limite meridional da banquisa estacional; 3 - limite de inlandsis ou de glaciação de montanha; 4 - área de interacção entre inlandsis; 5 - limite de zona climática oceânica (a - zona polar ou subpolar; b-zona temperada; c - zona subtropical); 6 - limite meridional do permafrost contínuo; 7 - limite meridional do permafrost descontínuo ou esporádico; 8 - limite meridional do solo gelado estacional profundo.

Fig. 1 - Paleogeographic conditions of the Western Europe and the North Atlantic, during the Maximum Cooling of the Last Glaciation (about 20,000 to 18,000 B.P.). After the Atlas of Paleoclimates... (Frenzel et al., 1992, pp. 49 and 59; simplified). 1 - Southern limit of perennial sea-ice; 2 - southern limit of seasonal sea-ice; 3 -ice sheet limit or boundary of mountain glaciation; 4 - area of interacting ice sheets; 5 -limit of climatic zone in the ocean ( $a$-polar and subpolar; $b$-temperate; $c$-subtropical); 6 - southern limit of continuous permafrost; 7 - southern limit of discontinuous or sporadic permafrost; 8 - boundary of deep seasonal freezing.

aproximada de $42^{\circ} \mathrm{N}$, ao largo da Galiza. Outra característica fundamental é a extensão da banquisa, durante o Inverno (Fevereiro), até ao Golfo da Gasconha, embora no Verão recuasse até à Islândia e Norte da Escandinávia, isto é, próximo dos limites meridionais actuais da banquisa de Inverno. Estas grandes variações da extensão da banquisa reflectir-se-iam certamente numa acentuada variação estacional da evaporação oceânica e provavelmente, também, na circulação sobre o Atlântico Norte. 


\section{SIGNIFICADO CLIMÁTICO DO SOLO GELADO PERMANENTE}

Desde as investigações pioneiras de Poser (1948), se conhece a distribuição aproximada do permafrost ao sul do inlandsis Norte-Europeu. O permafrost constituia uma faixa que se alargava para leste, à medida que o clima se tornava mais seco. Desde então houve grandes progressos nas investigações glaciárias e periglaciárias, sendo hoje possível cartografar, com bastante rigor, os sucessivos limites entre o inlandsis e o permafrost e, embora de maneira menos precisa, o limite meridional deste.

O desenvolvimento do permafrost resulta, antes do mais, de um balanço térmico negativo à superfície da Terra. Mas, no seu limite meridional, o solo gelado permanente depende muito de outras condições ambientais: existência ou não de toalhas líquidas, regime da neve, natureza dos solos e das rochas, natureza e grau de recobrimento da vegetação. Isso significa que, quando as temperaturas não forem suficientemente baixas, características locais da superfície da Terra podem favorecer ou desfavorecer o desenvolvimento do permafrost e este poder apresentar-se contínuo, descontínuo ou mesmo esporádico, na sua distribuição espacial. Por sua vez, o limite meridional do permafrost variou muito durante o Quaternário, revelando-se muito sensível às variações de temperatura, tornando-se, assim, um precioso indicador das variações climáticas.

Tem havido algumas tentativas de relacionar a distribuição do permafrost com as temperaturas médias anuais da atmosfera (observações de superfície). No Canadá, para o permafrost actual, BRown e PÉwé (1973) sugeriram a seguinte correlação entre as temperaturas médias anuais do ar e o limite meridional do permafrost: entre $-6^{\circ} \mathrm{C}$ e $-10^{\circ} \mathrm{C}$, para o permafrost contínuo; $-4^{\circ} \mathrm{C}$, para o permafrost descontínuo; $-1^{\circ} \mathrm{C}$, para o permafrost esporádico. A conclusões não muito diferentes chegaram BALLANTYNE e HARRIS (1994), na sua síntese sobre os ambientes periglaciários no Reino Unido. Estes autores consideram que o permafrost contínuo exige temperaturas médias anuais abaixo de $-6^{\circ} \mathrm{C}$ a $-8^{\circ} \mathrm{C}$, enquanto ao permafrost descontínuo correspondem temperaturas médias anuais que podem variar entre $-1^{\circ} \mathrm{C} e-8^{\circ} \mathrm{C}$.

Vimos já que, segundo o Atlas dos Paleoclimas e Paleoambientes (FrenZEL et al., 1992), o limite meridional do permafrost descontínuo e esporádico não ultrapassaria, no período de Máximo Arrefecimento da Última Glaciação, o Sul da França, e que apenas o Norte de Espanha seria afectado, de maneira generalizada, por um solo gelado estacional profundo. Se transpusermos para a Europa do Sudoeste o sinal climático admitido por Brown e Péwé (1973) e por BALLANTYNE e HARRIS (1994), isso significaria que na maior parte da Península Ibérica, durante o período de arrefecimento máximo, as temperaturas médias anuais seriam, de um modo geral, positivas. Mais uma vez, é preciso sublinhar que estamos a falar em termos zonais: é evidente que em ambiente de montanha as condições poderiam ser bem diversas, de maior rigor climático, como o atestam, de resto, as manifestações glaciárias e periglaciárias. 


\section{CONDIÇÕES AMBIENTAIS NA PENÍNSULA IBÉRICA DURANTE A GLACIAÇÃO PLISTOCÉNICA}

\section{O registo glaciário e os limites das neves perpétuas}

Há pouco mais de trinta anos, Messerli (1967) publicou um sugestivo esboço da distribuição dos limites das neves perpétuas (l.n.p.) em torno do Mediterrâneo, com base nos vestígios glaciários atribuídos à última glaciação. A análise desse documento permite retirar as seguintes conclusões quanto à distribuição dos l.n.p. na Península Ibérica e no Norte de África:

a) Na Península Ibérica, existência de gradientes muito acentuados na Cordilheira Cantábrica e nos Pirenéus. No primeiro caso, o gradiente muito acentuado deve estar relacionado com a importante barreira montanhosa que se interpõe ao fluxo húmido vindo do Golfo da Gasconha. No caso dos Pirenéus, o grande abaixamento dos l.n.p. do lado francês, em relação ao flanco espanhol, deve significar, essencialmente, que os Pirenéus constituíram, durante a glaciação, uma eficaz barreira aos fluxos de ar frio vindos de norte, colocando a Península Ibérica numa situação de abrigo. Esta ideia foi defendida por Frenzel e colaboradores (FRENZEL et al., 1992, p. 98).

b) Existência de um forte gradiente dos l.n.p. no Norte de África. Este é particularmente nítido no Mediterrâneo Ocidental, na transição do mar para a montanha do Atlas, mas parece prolongar-se para Oeste e, de uma maneira menos acentuada, parece existir também no Mediterrâneo Oriental, onde nenhum obstáculo montanhoso permite explicar um acentuado aumento dos l.n.p. na passagem do mar para o continente. Assim, a regularidade deste gradiente leste-oeste, para além das condições fisiográficas, poderá também significar a posição latitudinal da passagem da frente polar atmosférica para as altas pressões subtropicais. No entanto, é preciso ter em atenção que essa mesma ideia pode ter influenciado Messerli no traçado dos l.n.p., nomeadamente na margem Sul do Mediterrâneo Oriental, onde não há vestígios glaciários.

No caso particular do Noroeste peninsular, parece indubitável a existência de um forte gradiente dos l.n.p. na transição do oceano para o continente, ideia já antiga, bem expressa por Nussbaum e GygaX (1952), mas que foi confirmada por diversos trabalhos posteriores. Assim, Schmitz (1969), com base em vestígios glaciários (pouco claros, diga-se) em Faro de Avión, na Galiza meridional, determina um l.n.p. a $900 \mathrm{~m}$ de altitude, que passaria a ser o mais baixo de toda a Península. Os resultados da investigação de SCHMIDT-Thomé $(1973,1978)$ na Serra do Gerês e de Coudé-Gaussen $(1978,1979,1981)$ nas serras da Peneda e do Gerês, em grande parte confirmados por investigações 
mais recentes (Coudé et al., 1983; VidAl-Romaní et al., 1990; FERREIRA et al., 1992; FERREIRA et al., 1999), são também concordantes com este rápido abaixamento do l.n.p. em direcção ao oceano. PÉrez AlberTi et al. (1993) defenderam mesmo que o l.n.p. teria descido a $800 \mathrm{~m}$, de modo a explicar vestígios glaciários de tão baixa altitude como os da Serra do Xistral, no extremo norte da Galiza. No entanto, Valcárcel Díaz e Pérez Alberti (1998) adoptam agora uma interpretação mais conservadora, sugerindo uma altitude de $900 \mathrm{~m}$ para a «linha de equilíbrio glaciário» (equivalente do l.n.p.) da mesma montanha.

\section{As manifestações periglaciárias e o seu significado climático}

WASHBURN (1979), com base em vários trabalhos sobre as manifestações periglaciárias herdadas na Europa Ocidental, calculou o aumento mínimo da temperatura anual desde então, ou, o que equivale ao mesmo, a descida mínima da temperatura anual, em relação aos valores actuais, durante o período em que essas manifestações se desenvolveram. Entre os vestígios mais utilizados contam-se os das cunhas de gelo, que testemunham uma temperatura média anual de $-5^{\circ} \mathrm{C}$ ou mais baixa. Assim, foi calculada uma descida mínima de $8^{\circ} \mathrm{C}$ a $17^{\circ} \mathrm{C}$, conforme os lugares. No caso da Península Ibérica, onde não há vestígios seguros de antigas cunhas de gelo, o critério utilizado foi a comparação entre os limites inferiores actuais e herdados da solifluxão nas montanhas peninsulares, com base nas investigações de BROsche (1978). Efectivamente, BROSCHE $(1978,1982)$ verificou que, no limite inferior da solifluxão actual em Espanha, as temperaturas do ar são as seguintes: dois a seis meses com temperatura média inferior a $0^{\circ} \mathrm{C}$; temperaturas de Julho e Agosto variando entre 10 e $14^{\circ} \mathrm{C}$; temperaturas médias anuais entre 2,7 e $6^{\circ} \mathrm{C}$, conforme os lugares. Comparando os limites de altitude da solifluxão actual e herdada, chega à conclusão que a descida mínima da temperatura durante a última glaciação seria da ordem de $8-10^{\circ} \mathrm{C}$, tanto nas temperaturas mensais como anuais.

Nos últimos vinte anos, o conhecimento científico das manifestações periglaciárias da Península Ibérica sofreu importantes progressos, nomeadamente em Espanha, como se pode inferir da recente síntese coordenada por GómEZ ORTIZ et al. (1994). Apesar de uma clara diversidade regional, confirma-se a fraca representação dos vestígios de cunhas de gelo e de outras manifestações típicas do permafrost, e a nítida dominância dos depósitos crioclásticos de vertente, como é habitual nas montanhas mediterrâneas. No que se refere ao abaixamento de temperatura que essas manifestações periglaciárias podem testemunhar, os cálculos não diferem muito dos valores obtidos por BROSCHE. Por exemplo, no que se refere à Cordilheira Central espanhola, PEDRAZA (1994, p. 107) refere que o limite inferior das formas periglaciárias actuais se encontra a 1900-2000 m, enquanto durante o Plistocénico superior esse limite se

situaria a 500-600 m. Aplicando um gradiente térmico de $0,6^{\circ} \mathrm{C} / 100 \mathrm{~m}$, o abaixamento de temperatura que se obtém é um pouco supe- 
rior a $8^{\circ} \mathrm{C}$. Bem diferente é o cálculo que fazem VALCÁRCEl DíAz et al. (1998) para a descida da temperatura no período de máximo arrefecimento da Galiza (que, no entanto, segundo os autores, é posterior ao máximo glaciário), em que as temperaturas médias anuais teriam descido 12 a $14^{\circ} \mathrm{C}$, em relação às actuais. Isso significaria colocar a isotérmica anual dos $0^{\circ} \mathrm{C}$ ao nível do mar (ob. cit., p. 769; supõe-se que os autores se referem ao nível do mar actual). De acordo com os mesmos autores, na chamada "fase geocriológica interna» (designação atribuída à fase de arrefecimento máximo), o limite do permafrost descontínuo situar-se-ia, na Galiza, a cerca de $700 \mathrm{~m}$ de altitude (ob. cit., p. 768).

\section{ARREFECIMENTO EM PORTUGAL DURANTE A GLACIAÇÃO}

Segundo o Atlas de Paleoclimas e Paleoambientes (Frenzel et al., 1992), durante o período de Máximo Arrefecimento da Última Glaciação, os valores mínimos da descida da temperatura na Península Ibérica seriam, no mês mais frio (Fevereiro), de $10^{\circ} \mathrm{C}$ a $12^{\circ} \mathrm{C}$, e, no mês mais quente (Agosto), de $6^{\circ} \mathrm{C}$ a $8^{\circ} \mathrm{C}$.

Estes valores ajustam-se ao arrefecimento que é possível inferir das manifestações periglaciárias herdadas que ocorrem na Península Ibérica, como acabámos de ver. No caso particular de Portugal, num trabalho anterior (FERREIRA, 1985), a propósito das manifestações de climas frios na região a norte de Lisboa, propusemos uma descida de temperatura da ordem de $8-10^{\circ} \mathrm{C}$, tal como o defendera BRosche para a Espanha. Sendo as cascalheiras crioclásticas a manifestação mais comum do periglaciarismo não só na região de Lisboa como em todo o país, essa proposta de arrefecimento teve em conta os resultados de análise laboratorial sobre crioclastia efectuados no Centro de Geomorfologia de Caen, durante vinte anos, em vários tipos de rochas, e resumidos na tese de LAUTRIDOU (1984).

Um outro indício de arrefecimento de que se dispõe é o do nível das neves perpétuas, tanto para a glaciação da Serra da Estrela como para a glaciação da Serra do Gerês. Como se sabe, o limite das neves perpétuas corresponde a uma altitude em que se verifica um equilíbrio entre a acumulação e a fusão das neves, ou seja, a altitude a partir da qual as neves podem permanecer de ano para ano, permitindo a formação do nevado e dos glaciares. Ora essa altitude depende de inúmeros factores, tais como a precipitação nivosa, o regime dos ventos, a radiação solar e a temperatura do ar. É evidente que o limite das neves perpétuas (l.n.p.) é mais influenciado pelas temperaturas de Verão do que pelas de Inverno, porque é delas que depende essencialmente a taxa de ablação das neves.

Se adoptássemos para as regiões de montanha o critério de KöPPEN para a definição dos desertos polares, o l.n.p. corresponderia, teoricamente, a uma temperatura média do mês mais quente do ano $\left(t_{12}\right)$ igual a $0^{\circ} \mathrm{C}$. Na prática, verifica-se que os glaciares de montanha podem formar-se ou persistir com temperaturas positivas no Verão, dependendo em grande parte da taxa de acumulação na ELA («equilibrium line altitude»), ou seja, no limite entre a área 
de acumulação e a área de ablação glaciária (mais concretamente, entre a área em que a acumulação predomina sobre a ablação e a área em que a ablação predomina sobre a acumulação). De acordo com Lowe e WALKER (1997), do ponto de vista da reconstituição das paleotemperaturas ELA e FLA («firn line altitude», isto é, o nível das neves perpétuas) são equivalentes. Os mesmos autores referem estudos que mostram um aumento da temperatura de Verão da ELA com a taxa de acumulação nivosa à mesma altitude, podendo aquela atingir valores da ordem de $4^{\circ} \mathrm{C}$.

Para a glaciação da Serra da Estrela, foi estimado um l.n.p. de $1650 \mathrm{~m}$ (LaUtensach, 1929; Daveau, 1971), enquanto, para a glaciação da Serra do Gerês, Coudé-Gaussen (1981) propõe um valor entre 1100 e 1200 m. Partindo dos valores actuais de $t_{12}$ e do respectivo gradiente térmico altitudinal, da ordem de $0,5^{\circ} \mathrm{C} / 100 \mathrm{~m}$, (inferior ao gradiente regional das temperaturas médias anuais, que é de $0,55^{\circ} \mathrm{C} / 100 \mathrm{~m}$, e ambos inferiores ao gradiente médio na troposfera terrestre, ou seja, $0,65^{\circ} \mathrm{C} / 100 \mathrm{~m}$; ver, por exemplo, LockwOOD, 1985, p. 90), e considerando a hipótese de uma descida de $10^{\circ} \mathrm{C}$, encontramos para o l.n.p. da Serra da Estrela um valor de $t_{12}=5,3^{\circ} \mathrm{C}$ e, para o l.n.p. da Serra do Gerês, um valor mínimo (isto é, considerando o l.n.p. $=1200 \mathrm{~m}$ e o gradiente térmico das estações de registo que apresentam, para as mesmas altitudes, temperaturas mais baixas) de $\mathrm{t}_{12}=6,3^{\circ} \mathrm{C}$ (Fig. 2). No l.n.p. da Serra da Estrela, a temperatura média anual seria de $-2,8^{\circ} \mathrm{C}$ e haveria quatro meses no ano com temperatura média positiva. No caso do l.n.p. da Serra do Gerês, a temperatura média anual seria de $-1,4^{\circ} \mathrm{C}$ e haveria também quatro meses no ano com temperatura média positiva.

Admitindo agora a hipótese do Atlas de Paleoambientes e Paleoclimas de que, na Península Ibérica, durante o Máximo Arrefecimento da Última Glaciação, a descida térmica no Verão $\left(6\right.$ a $\left.8^{\circ} \mathrm{C}\right)$ teria sido inferior à de Inverno $\left(10\right.$ a $\left.12^{\circ} \mathrm{C}\right)$, considerámos o cenário de uma descida de $10^{\circ} \mathrm{C}$ em Janeiro e Fevereiro, $9^{\circ} \mathrm{C}$ em Março e Dezembro, $8^{\circ} \mathrm{C}$ em Abril e Novembro, $7^{\circ} \mathrm{C}$ em Maio e Outubro, e de $6^{\circ} \mathrm{C}$ em Junho, Julho, Agosto e Setembro. Nessas condições, no l.n.p. da Serra da Estrela a temperatura média anual seria de $-0,4^{\circ} \mathrm{C}$, havendo seis meses de temperatura média positiva, com $t_{12}=9,5^{\circ} \mathrm{C}$. No l.n.p. da Serra do Gerês, a temperatura média anual seria de $1^{\circ} \mathrm{C}$, também com seis meses de temperatura média positiva e $\mathrm{t}_{12}=10,2^{\circ} \mathrm{C}$.

Este último cenário parece-nos menos provável, mesmo tendo em conta condições locais muito favoráveis à formação de glaciares, tais como: 1) elevada precipitação nivosa (sobretudo no Gerês); 2) fraca insolação de Verão (sobretudo no Gerês); 3) condições favoráveis à acumulação da neve (em posição de abrigo e em superfícies planas, tanto no Gerês como na Serra da Estrela). Por sua vez, a condição $t_{12}=0^{\circ} \mathrm{C}$ implicaria uma descida da temperatura da ordem de 15 a $16^{\circ} \mathrm{C}$ (Fig. 2), cenário que se afigura muito exagerado em relação ao contexto paleogeográfico em que Portugal se insere e à natureza e localização das manifestações glaciárias e periglaciárias reconhecidas até hoje no país. Assim, a descida térmica estival da ordem de $10^{\circ} \mathrm{C}$ parece-nos o cenário mais ajustado. 


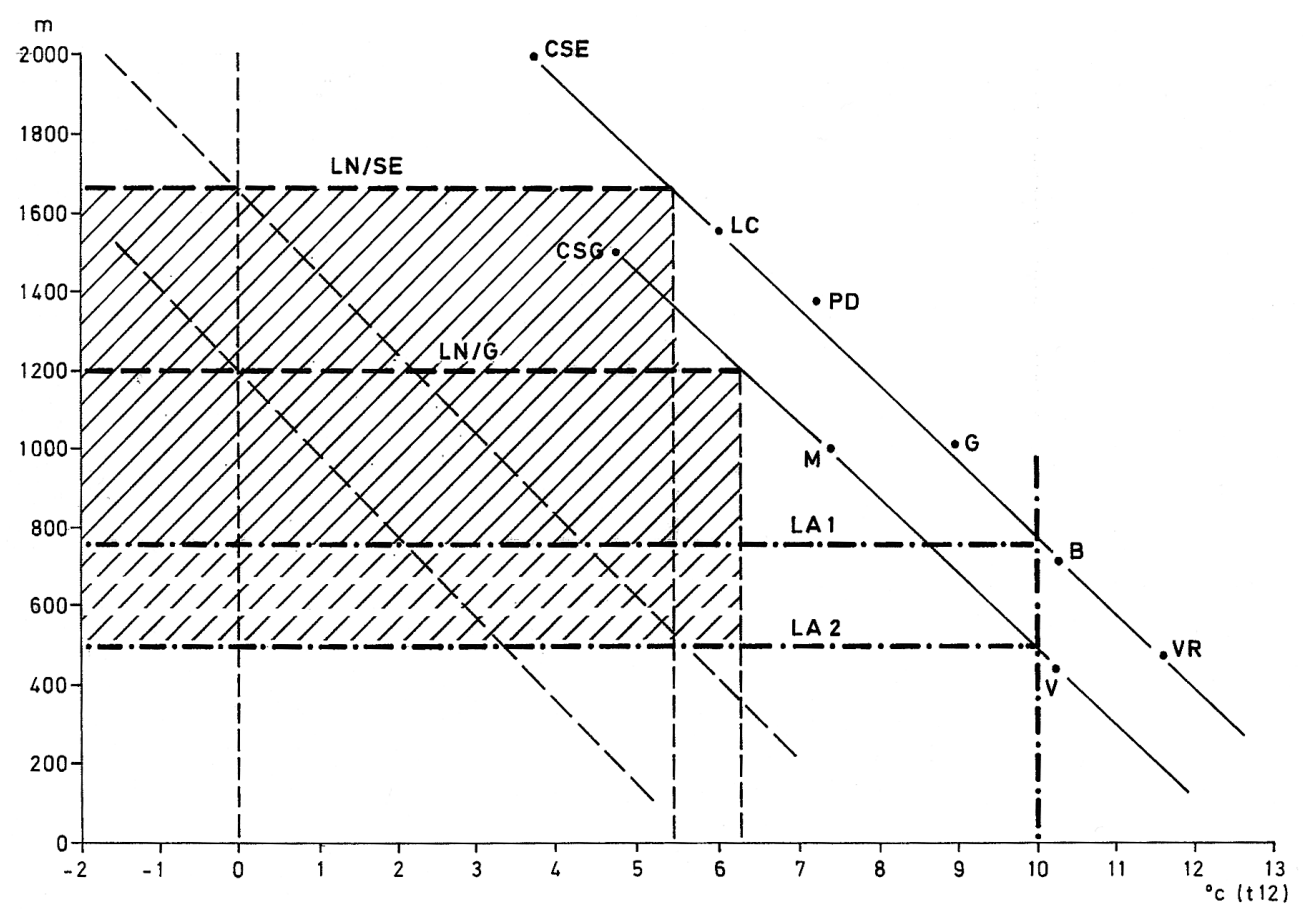

Fig. 2 - Gradientes térmicos altitudinais do mês mais quente $\left(t_{12}\right)$, supondo uma descida de $10^{\circ} \mathrm{C}$ em relação aos valores actuais (linhas em diagonal, contínuas). LN/SE, altitude do l.n.p. da glaciação da Serra da Estrela; LN/G, altitude do l.n.p. da glaciação da Serra do Gerês; LA 1 e LA 2, limites superiores da árvore $\left(\mathrm{t}_{12}=10^{\circ} \mathrm{C}\right)$, para os dois gradientes térmicos considerados. A faixa tracejada corresponde ao hipotético andar alpino (entre o l.n.p. e o L.A.). As linhas em diagonal descontínuas mostram o arrefecimento necessário se considerássemos um $\mathrm{t}_{12}=0^{\circ} \mathrm{C}$, ao nível das neves perpétuas ( 15 a $16^{\circ} \mathrm{C}$, em relação às temperaturas actuais). $\mathrm{B}$ - Bragança; CSE - Cimo da Serra da Estrela; CSG - Cimo da Serra do Gerês; G - Guarda; LC - Lagoa Comprida; M - Montalegre; PD - Penhas Douradas; V - Viseu; VR - Vila Real.

Fig. 2 - Temperature lapse rates in summer (warmest month $=t_{12}$ ), supposing a decrease of $10^{\circ} \mathrm{C}$ on the present values. $L N / S E$, firn line altitude of the Serra da Estrela pleistocene glaciation; $L N / G$, firn line altitude of the Serra do Gerês pleistocene glaciation; LA, tree line $\left(t_{12}=10^{\circ} \mathrm{C}\right)$ considering the two observed temperature lapse rates. The hatched belt shows the hypothetical alpine zone (between the firn line and the tree line).

Reconhece-se o carácter muito hipotético desta tentativa de reconstituição da paleotemperatura de Verão em Portugal durante a glaciação plistocénica. No entanto, os resultados obtidos afiguram-se-nos como um cenário possível, e até provável, atendendo ao contexto ambiental em que Portugal se inseria, e que impõe certos limites a interpretações radicais, quer no sentido de um arrefecimento muito intenso quer, pelo contrário, da manutenção de condições atmosféricas muito favoráveis durante o período glaciário. Os maiores problemas da proposta apresentada residem, por um lado, na ignorância em que nos encontramos do verdadeiro ritmo da insolação durante a glacia- 
ção, e, acima de tudo, na falta de cronologia absoluta para as manifestações glaciárias e periglaciárias que, em última análise, podem corresponder a fases diversas do Plistocénico. A ideia, geralmente aceite, de que o essencial das manifestações glaciárias da Península Ibérica se deve à Última Glaciação, parece desmentida pela aplicação recente de uma nova técnica de datagem absoluta aplicada a vestígios da glaciação da Serra do Gerês e da vizinha Serra da Queixa, situada a cerca de $80 \mathrm{~km}$ a nordeste do Gerês (VIDAL Romaní et al., 1999). Essa técnica, que se baseia nos efeitos da radiação cósmica sobre superfícies postas a descoberto pelos glaciares, forneceu resultados que sugerem uma fase de máximo pertencente à Penúltima Glaciação (Riss, na cronologia alpina) na Serra da Queixa, ou até mais antiga, no caso da Serra do Gerês. Na Serra da Queixa, as idades obtidas permitem também reconhecer fases glaciárias atribuíveis ao Último Pleniglaciário e ao Tardiglaciário. A permanência de condições glaciárias e periglaciárias até uma fase tardia do Plistocénico, é sugerida igualmente pela ausência de sedimentação turfosa nas montanhas do Noroeste peninsular antes do Dryas Antigo (RAmil Rego et al., 1995; Vidal Romaní et al., 1995), o que também acontece na Serra da Estela (Van Der Knapp e Van Leeuwen, 1997).

\section{BIBLIOGRAFIA}

Ballantyne, C. K.; Harris, C. (1994) - The Periglaciation of Great Britain. Cambridge Univ. Press, Cambridge.

Brosche, K. U. (1978) - Formas actuales y límites inferiores periglaciares en la Península Ibérica. Estudios Geográficos, XXXIX, 151: 131-161.

Brosche, K. U. (1982) - Formas periglaciares antiguas en la Península Ibérica. Posibilidades de una consideración climática. Estudios Geográficos, XLIII, 166: 5-16.

Brown, R. J. E.; PÉwÉ, T. L. (1973) - Distribution of permafrost in North America and its relationship to the environment: a review, 1963-1973. In North Am. Cont., Permafrost Second Int. Conf., Nat. Acad. Sc., Washington: 71-100.

Climap Project Members (1976) - The Surface of the Ice-Age Earth. Science, 191: 1131-1137.

Coudé, A.; Coudé-Gaussen, G.; Daveau, S. (1983) - Nouvelles observations sur la glaciation des montagnes du Nord-Ouest du Portugal. Cuad. Lab. Xeol. Laxe: 5: 381-393.

Coudé-Gaussen, G. (1978) - Confirmation de l'existence d'une glaciation wurmienne dans les montagnes du Nord-Ouest du Portugal. C. R. Somm. Soc. Géol. France, 1, Paris: 34-37.

Coudé-Gaussen, G. (1979) - Les Serras da Peneda et do Gerês (Minho-Portugal). Formes et formations d'origine froide en milieu granitique. Thèse Univ. Paris I.

Coudé-Gaussen, G. (1981) - Les Serras da Peneda et do Gerês. Étude géomorphologique. Memórias C.E.G., 5, Lisboa.

Daveau, S. (1971) - La glaciation de la Serra da Estrela. Finisterra. Revista Portuguesa de Geografia, VI (11), Lisboa: 5-40.

Daveau, S. (1973) - Quelques exemples d'évolution quaternaire des versants au Portugal. Finisterra. Revista Portuguesa de Geografia, VIII (15), Lisboa: 5-45. 
Daveau, S. (1978) - Le périglaciaire d'altitude au Portugal. In Colloque sur le périglaciaire d'altitude du domaine méditerranéen et abords, Assoc. Géogr. Alsace, Strasbourg: 63-78.

FERREIRA, A. B. (1985) - Influência de climas frios na morfogénese quaternária da região a norte de Lisboa. In Actas I Reunião Quat. Ibérico, I, Lisboa: 85-103.

Ferreira, A. B.; Vidal-Romani, J. R.; Vilaplana, J. M.; Rodrigues, M. L.; Zêzere, J. L.; Monge, C. (1992) - Formas e depósitos glaciários e periglaciários da Serra do Gerês-Xurés (Portugal; Galiza). Levantamento cartográfico. Cuad. Lab. Xeol. Laxe, 17: 121-135.

Ferreira, A. B.; Vidal-Romani, J. R.; Zêzere, J. L.; Rodrigues, M. L. (1999) - A glaciação plistocénica da Serra do Gerês. Vestígios geomorfológicos e sedimentológicos. A.G.F.A., Rel. 37, Centro de Estudos Geográficos, Lisboa.

Frenzel, B.; Pécsi, M.; VelichKo, A. A. (1992) - Atlas of Paleoclimates and Paleoenvironments of the Northern Hemisphere, Late Pleistocene-Holocene. Geogr. Res. Inst., Hungarian Acad. Sc., Budapest.

Gómez Ortiz, A.; Simón Torres, M.; Salvador Franch, F. (eds.) (1994) - Periglaciarismo en la Península Ibérica, Canarias y Baleares. Universidad de Granada.

Hecht, A. D. (1985) - Paleoclimatology: a retrospective of the past 20 years. In A. D. Hecht (ed.), Paleoclimatic Analysis and Modeling, J. Wiley, N. York: 1-25.

Lautensach, H. (1929) - Eiszeitstudien in der Serra da Estrela (Portugal). Zeits. f. Gletscherkunde, XVII: 324-369. Trad. port.: Estudo dos glaciares da Serra da Estrela. Memórias e Notícias, 1932, VI: $1-60$.

Lautridou, J. P.(1984) - Le cycle périglaciaire pleistocène en Europe du Nord-Ouest et plus particulièrement en Normandie. Thèse Univ. Caen.

Lockwood, J. G. (1985) - World Climatic Systems. E. Arnold, Londres.

Lowe, J. J.; WALKeR, M. J. C. (1997) - Reconstructing Quaternary Environments. Longman, Sc. \& Tech., Essex, $2 .^{\mathrm{a}}$ ed.

Messerli, B. (1967) - Die eiszeitliche und die gegenwärtige Vergletscherung in Mittelmeerraum. Geographica Helvetica, 22, 3: 105-228.

Nussbaum, R. Y.; GygaX, E. (1952) - La glaciation quaternaire dans la Cordillère Cantabrique (Espagne du Nord). Rev. Géogr. Pyr. SO, 23: 36-48.

Pedraza Gilsanz, J. (1994) - Periglaciarismo del Sistema Central Español. In A. Gómez Ortiz; M. Simón Torres; F. Salvador Franch (eds.) - Periglaciarismo en la Península Ibérica, Canarias y Baleares, Universidad de Granada: 147-164.

Pérez Alberti, A.; Guitián Rivera, L.; Valcárcel Díaz, M. (1993) - Las formas y depósitos glaciares en las Sierras Orientales y Septentrionales de Galicia (NW Península Ibérica). In A. Pérez Alberti; L. Guitián Rivera; P. Ramil Rego (eds.) - La Evolución del Paisaje en las Montañas del Entorno de los Caminos Jacobeos. Xunta de Galicia, Santiago: 61-90.

Poser, H. (1948) - Boden und Klimaverhältnisse in Mittel und Westeuropa während der Würmeiszeit. Erdkunde, 2: 53-68.

Ramil-Rego, P.; Aira Rodríguez, M. J.; Alonso Mattias, F. (1995) - Caracterización climática y vegetacional de la Serra de Gerês (Portugal) durante el Tardiglaciar y el Holoceno: análisis polínico de A Lagoa do Marinho. In Actas 3. ${ }^{a}$ Reun. Quat. Ibérico, Coimbra (1993): 85-92.

Schмidт-Tноме́, P. (1973) - Neue, niedrig gelegene Zeugen einer würmeiszeitlichen Vergletscherung in Nordteil der Iberischen Halbinsen (Prov. Vizcaya und Orense in Nordspanien; Minho-Distrikt in Nordportugal). Eiszeitalter u. Gegenwart, 23/24: 384-389. 
Schmidt-Thомé, P. (1978) - Nuevos testigos de una glaciación wurmiense extensa y de altura muy baja en el Noroeste de la Península Ibérica (Orense, España y Minho/Trás-os-Montes, Portugal. Cuad. Sem. Est. Cerám. Sargadelos, 37: 221-243.

Scmitz, H. (1969) - Glazialmorphologische Untersuchungen im Bergland Nordwestspaniens (Galicien/León). Kölner Geogr. Arb., 23.

Valcárcel Díaz, M.; Pérez Alberti, A. (1998) - Límite máximo de la glaciación y línea de equilibrio glaciar en el noroeste de la Península Ibérica durante el último período frío». In A. Gómez Ortiz; F. Salvador Franch; L. Schulte, L.; A. García Navarro (eds.) - Investigaciones Recientes de la Geomorfología Española. Aportaciones a la V Reunión Nacional de Geomorfología (Granada, 1998). Univ. de Barcelona: 455-462.

Valcárcel Díaz, M.; Blanco Chao, R.; Martínez Cortizas, A.; Pérez Alberti, A. (1998) - Estimación de las paleotemperaturas en Galicia durante el último ciclo glaciar a partir de datos geomorfológicos y climáticos. In A. Gómez Ortiz; F. SALVAdor Franch; L. SchUlte; A. García NAVARRo (eds.) - Investigaciones Recientes de la Geomorfología Española. Aportaciones a la V Reunión Nacional de Geomorfología (Granada, 1998), Univ. de Barcelona: 767-770.

VAN Der Knapp, W. O.; VAn Leeuwen, J. F. N. (1997) - Late Glacial and early Holocene vegetation succession, altitudinal vegetation zonation, and climate change in the Serra da Estrela, Portugal. Review of Paleobotany and Palynology, 97: 239-285.

Vidal Romani, J. R.; Santos Fidalgo, L.; Jalut, G. (1995) - Cronología relativa del máximo glaciar finipleistoceno en el sector Nor-Oriental de la Serra de Queixa (Ourense, Galicia, España). In Actas 3. ${ }^{a}$ Reun. Quat. Ibérico, Coimbra (1993): 215-222.

Vidal Romaní, J. R.; Fernandez Mosquera, D.; Marti, K.; Brum Ferreira, A. (1999) - Nuevos datos para la cronología glaciar pleistocena en el NW de la Península Ibérica. Cuadernos Lab. Xeolóxico de Laxe, 24: 7-29.

WASHBurn, A. L. (1979) - Geocryology. A survey of periglacial processes and environments. E. Arnold, Londres. 